\title{
Power Quality Improvement of Large Power System Using a Conventional Method
}

\author{
Nazmus Sahadat, Shakhawat Hossain, Arifur Rahman, Sharif Taufique Atique, Md. Touhiduzzaman \\ Department of Electrical and Electronic Engineering, Bangladesh University of Engineering and Technology, Bangladesh \\ E-mail:m.n.sahadat@gmail.com \\ Received May 7, 2011; revised May 25, 2011; accepted June 5, 2011
}

\begin{abstract}
Operation of a large power system with maintaining proper power quality is always been a difficult task. It becomes more difficult to maintain the power quality when rapid expansion of previously designed power system occurred. To redesign of such a power system is not feasible and also cost effective. To improve the quality of power of such a large system, conventional methods of compensation can be used. In this paper a power system of 419 buses is analyzed. It is found that 76 buses have under voltage problem. Conventional shunt compensation method is used by connecting capacitor in parallel to the bus. After compensation the system is simulated again and found that the under voltage problem of this large power system is removed. Power factor of the system is also improved.
\end{abstract}

Keywords: Shunt Compensation, Power Quality, under Voltage, Power Factor, Power Flow, PSAF

\section{Introduction}

The necessity of energy is increasing day by day. With the development of more sensitive electronic appliances it is mandatory to maintain the quality of power. Many valuable devices can be burnt out due to the cause of low power quality. In the industrial application power quality is most important. Big economical loss can occur due to power quality.

Under voltage problem of large power system is a very common problem. To solve this problem many methods can be used [1-4]. Shunt compensation in the buses is most common method among of them.

In this paper fixed capacitor is used to solve the under voltage problem of a large power system of Bangladesh. Load flow analysis is applied by PSAP of a 419 bus system before and after connecting fixed capacitor in the low voltage buses. Before connecting of fixed capacitor it is found that 76 buses have under voltage (below 0.9 p.u.). After connecting the fixed capacitor in 45 buses it is found that under voltage problem is totally solved and the power factor of the buses have also improved.

\section{Theory of Compensation}

Figure 1 shows the simplified model of a power transmission system. Two power grids are connected by a transmission line which is assumed lossless and represented by the reactance $\boldsymbol{X L} . V_{1}<\delta_{1}$ and $V_{2}<\delta_{2}$ represent the voltage phasors of the two power grid buses with angle $\delta=\delta_{1}-\delta_{2}$ between the two. The corresponding phasor diagram is shown in Figure 2.

The magnitude of the current in the transmission line is given by:

$$
I=V_{L} / X_{L}=\left(\left|V_{1}<\delta_{1}-V_{2}<\delta_{2}\right|\right) / X_{L}
$$

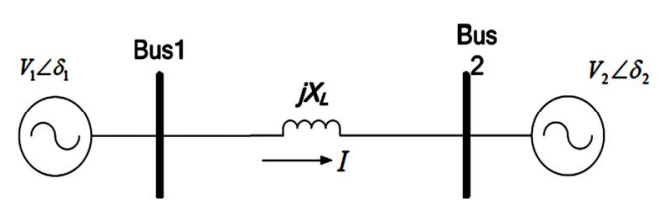

Figure 1. Simplified model of power transmission system.

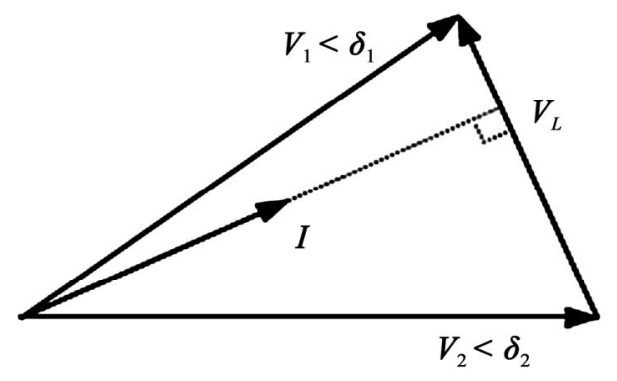

Figure 2. Phasor diagram of voltage and current. 
The active and reactive components of the current flow at bus 1 are given by:

$$
I_{d 1}=V_{2} \sin \delta / X_{L}, \quad I_{q 1}=\left(V_{1}-V_{2} \cos \delta\right) / X_{L}
$$

The active power and reactive power at bus 1 are given by:

$$
P_{1}=V_{1} V_{2} \sin \delta / X_{L}, \quad Q_{1}=V_{1}\left(V_{1}-V_{2} \cos \delta\right) / X_{L}
$$

Similarly, the active and reactive components of the current flow at bus 2 can be given by:

$$
I_{d 2}=V_{1} \sin \delta / X_{L}, \quad I_{q 2}=\left(V_{2}-V_{1} \cos \delta\right) / X_{L}
$$

The active power and reactive power at bus 2 are given by:

$$
P_{2}=V_{1} V_{2} \sin \delta / X_{L}, \quad Q_{2}=V_{2}\left(V_{2}-V_{1} \cos \delta\right) / X_{L}
$$

Equations (1)-(9) indicate that the active and reactive power/current flow can be regulated by controlling the voltages, phase angles and line impedance of the transmission system.

\section{Methods of Compensation}

The compensation of transmission systems can be divided into two main groups: shunt and series compensation [5].

\subsection{Series Compensation}

Series compensation aims to directly control the overall series line impedance of the transmission line. Tracking back to Equations (1)-(9), the AC power transmission is primarily limited by the series reactive impedance of the transmission line. A series-connected can add a voltage in opposition to the transmission line voltage drop, therefore reducing the series line impedance [6-8].

A simplified model of a transmission system with series compensation is shown in Figure 3. The voltage magnitudes of the two buses are assumed equal as $V$, and the phase angle between them is $\delta$. The transmission line is assumed lossless and represented by the reactance $X_{L}$. A controlled capacitor is series-connected in the transmission line with voltage addition $V_{i n j}$. The phase diagram is shown in Figure 4.

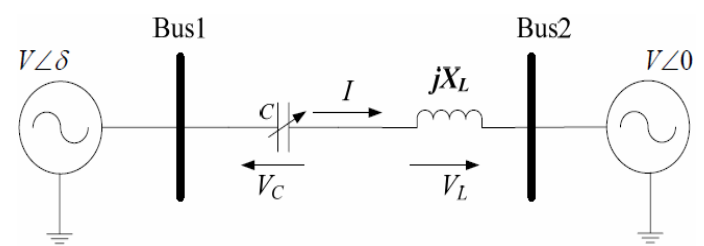

Figure 3. Simplified transmission system model with series compensation.
Defining the capacitance of $C$ as a portion of the line reactance,

$$
X_{C}=K X_{L}
$$

The overall series inductance of the transmission line is,

$$
X=X_{L}-X_{C}=(1-K) X_{L}
$$

The active power transmitted is,

$$
P=V^{2} /(1-K) X_{L} * \sin \delta
$$

The reactive power supplied by the capacitor is calculated as:

$$
Q_{C}=2 * V^{2} / X_{L} * K /\left(1-K^{2}\right) *(1-\cos \delta)
$$

In Figure 5 shows the power angle curve from which it can be seen that the transmitted active power increases with $K$.

\subsection{Shunt Compensation}

Shunt compensation, especially shunt reactive compensation has been widely used in transmission system to regulate the voltage magnitude, improve the voltage quality, and enhance the system stability [9]. Shunt-connected reactors are used to reduce the line over-voltages by consuming the reactive power, while shunt-connected capacitors are used to maintain the voltage levels by compensating the reactive power to transmission line.

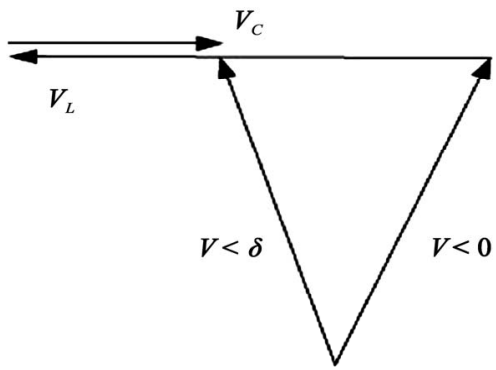

Figure 4. Phasor diagram of series compensated line voltages.

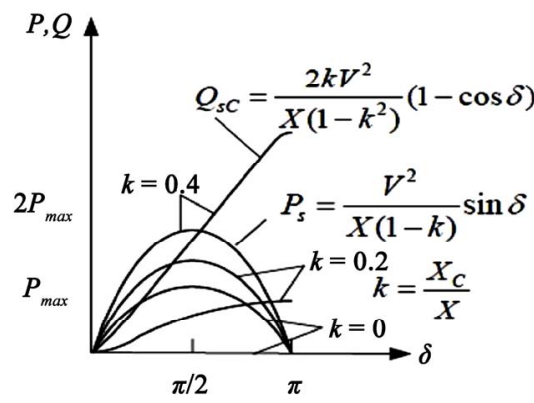

Figure 5. Power-angle curve. 
A simplified model of a transmission system with shunt compensation is shown in Figure 6. Figure 7 shows the phasor diagram of corresponding voltages and currents. The voltage magnitudes of the two buses are assumed equal as $V$, and the phase angle between them is $\delta$. The transmission line is assumed lossless and represented by the reactance $X_{L}$ At the midpoint of the transmission line; a controlled capacitor $C$ is shunt-connected. The voltage magnitude at the connection point is maintained as $V$.

As discussed previously, the active powers at bus 1 and bus 2 are equal.

$$
P_{1}=P_{2}=2 * V^{2} / X_{L} * \sin (\delta / 2)
$$

As discussed previously, the active powers at bus 1 and bus 2 are equal.

$$
Q_{C}=4 * V^{2} / X_{L} *\left(1-\cos \frac{\delta}{2}\right)
$$

From the power angle curve shown in Figure 8, the transmitted power can be significantly increased, and the peak point shifts from $\delta=90^{\circ}$ to $\delta=180^{\circ}$. The operation margin and the system stability are increased by the shunt compensation.

The voltage support function of the midpoint compensation can easily be extended to the voltage support at the end of the radial transmission, which will be proven by the system simplification analysis. The reactive power compensation at the end of the radial line is especially effective in enhancing voltage stability.

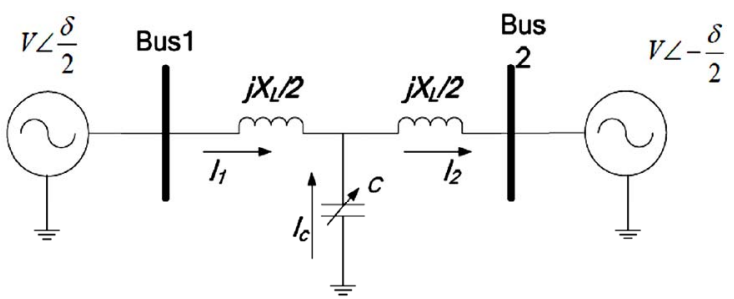

Figure 6. Simplified transmission system model with shunt compensation.

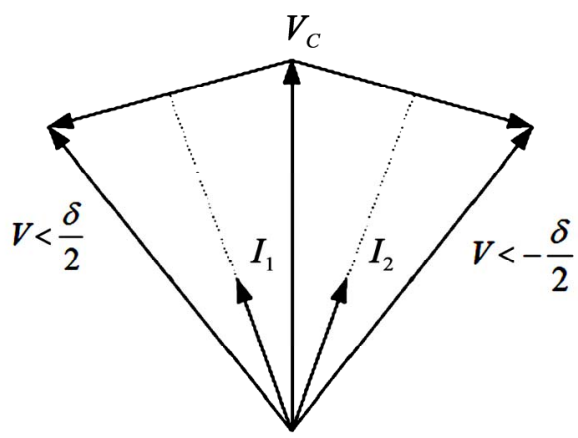

Figure 7. Phasor diagram of shunt compensated line voltages and currents.

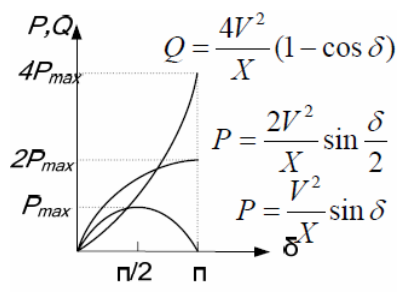

Figure 8. Power angle curve.

\section{Load Flow Analysis}

The goal of a power flow study is to obtain complete voltage angle and magnitude information for each bus in a power system for specified load and generator real power and voltage conditions [10]. Once this information is known, real and reactive power flow on each branch as well as generator reactive power output can be analytically determined. Due to the nonlinear nature of this problem, numerical methods are employed to obtain a solution that is within an acceptable tolerance.

The solution to the power flow problem begins with identifying the known and unknown variables in the system. The known and unknown variables are dependent on the type of bus. A bus without any generators connected to it is called a Load Bus. With one exception, a bus with at least one generator connected to it is called a Generator Bus. The exception is one arbitrarily-selected bus that has a generator. This bus is referred to as the Slack Bus.

In the power flow problem, it is assumed that the real power $P_{D}$ and reactive power $Q_{D}$ at each Load Bus are known. For this reason, Load Buses are also known as $P Q$ Buses. For Generator Buses, it is assumed that the real power generated $P_{G}$ and the voltage magnitude $|V|$ is known. For the Slack Bus, it is assumed that the voltage magnitude $|V|$ and voltage phase $\Theta$ are known. Therefore, for each Load Bus, both the voltage magnitude and angle are unknown and must be solved for; for each Generator Bus, the voltage angle must be solved for; there are no variables that must be solved for the Slack Bus. In a system with $N$ buses and $R$ generators, there are then $2(N-$ $1)-(R-1)$ unknowns.

In order to solve for the $2(N-1)-(R-1)$ unknowns, there must be $2(N-1)-(R-1)$ equations that do not introduce any new unknown variables. The possible equations to use are power balance equations, which can be written for real and reactive power for each bus. The real power balance equation is:

$$
0=-P_{i}+\sum_{k=1}^{N}\left|V_{i}\right|\left|V_{k}\right|\left(G_{i k} \cos \theta_{i k}+B_{i k} \sin \theta_{i k}\right)
$$

where,

$P_{i}=$ Net power injected at bus $i$.

$G_{i k}=$ Real part of the element in the bus admittance 
matrix $\mathrm{Y}_{\mathrm{BUS}}$ corresponding to the $i$ th row and $k$ th column.

$B_{i k}=$ Imaginary part of the element in the $\mathrm{Y}_{\mathrm{BUS}}$ corresponding to the $i$ th row and $k$ th column

$\theta_{i k}=$ Difference in voltage angle between the $i$ th and $k$ th buses.

The reactive power balance equation is:

$$
0=-Q_{i}+\sum_{k=1}^{N}\left|V_{i}\right|\left|V_{k}\right|\left(G_{i k} \sin \theta_{i k}-B_{i k} \cos \theta_{i k}\right)
$$

where,

$Q_{i}=$ Net reactive power injected at bus $i$.

Equations included are the real and reactive power balance equations for each Load Bus and the real power balance equation for each Generator Bus. Only the real power balance equation is written for a Generator Bus because the net reactive power injected is not assumed to be known and therefore including the reactive power balance equation would result in an additional unknown variable. For similar reasons, there are no equations written for the Slack Bus.

\subsection{Gauss-Seidel Method}

This method is based on substituting nodal equations into each other. It is the slower of the two but is the more stable technique. Its convergence is said to be Monotonic. The iteration process can be visualized for two equations:

Although not the best load-flow method, Gauss-Seidel is the easiest to understand and was the most widely used technique until the early 1970s.

\subsection{Newton Raphson Method}

There are several different methods of solving the resulting nonlinear system of equations. The most popular is known as the Newton-Raphson Method. This method begins with initial guesses of all unknown variables (voltage magnitude and angles at Load Buses and voltage angles at Generator Buses). Next, a Taylor Series is written, with the higher order terms ignored, for each of the power balance equations included in the system of equations. The result is a linear system of equations that can be expressed as:

$$
\left[\begin{array}{l}
\Delta \theta \\
\Delta|V|
\end{array}\right]=J^{-1}\left[\begin{array}{l}
\Delta P \\
\Delta Q
\end{array}\right]
$$

where, $\Delta P$ and $\Delta Q$ are called the mismatch equations:

$$
\begin{gathered}
\Delta P=-P_{i}+\sum_{k=1}^{N}\left|V_{i}\right|\left|V_{k}\right|\left(G_{i k} \cos \theta_{i k}+B_{i k} \sin \theta_{i k}\right) \\
\Delta Q=-Q_{i}+\sum_{k=1}^{N}\left|V_{i}\right|\left|V_{k}\right|\left(G_{i k} \sin \theta_{i k}-B_{i k} \cos \theta_{i k}\right)
\end{gathered}
$$

and $J$ is a matrix of partial derivatives known as a Jacobean:

$$
J=\left[\begin{array}{ll}
\frac{\delta \Delta P}{\delta \theta} & \frac{\delta \Delta P}{\delta|V|} \\
\frac{\delta \Delta Q}{\delta \theta} & \frac{\delta \Delta Q}{\delta|V|}
\end{array}\right]
$$

The linearized system of equations is solved to determine the next guess $(m+1)$ of voltage magnitude and angles based on:

$$
\begin{aligned}
& \theta^{m+1}=\theta^{m}+\Delta \theta \\
& |V|^{m+1}=|V|^{m}+\Delta|V|
\end{aligned}
$$

The process continues until a stopping condition is met. A common stopping condition is to terminate if the norm of the mismatch equations are below a specified tolerance.

\section{Simulation and Results}

Bangladesh power system is a big system of 419 buses. So the system is divided in to six zones and load flow study is applied in PSAP (Power System Analysis Program). Newton-Raphson method is used here for solving the load flow problem.

Load flow study is applied on the whole system without connecting any compensator. It is found that 76 buses have voltage under 0.9 p.u. To solve this under voltage problem fixed capacitors have installed in 44 buses of them. After adding fixed capacitors, load flow study is applied again and it is found that under voltage problem of whole system has removed. Power factor of the system has also improved. Table 1 shows the values of bus voltages in p.u. before and after connecting shunt capacitors.

The added values of shunt capacitors have also been calculated. Table 2 shows the added values of capacitors in micro Farad.

Table 1. Under Voltage Buses before and after Shunt Compensation.

\begin{tabular}{lccc}
\hline BUS ID & $\begin{array}{c}\text { Rated } \\
\text { value } \\
\text { (kV) }\end{array}$ & $\begin{array}{c}\text { Voltage before } \\
\text { compensation } \\
\text { [p.u.] }\end{array}$ & $\begin{array}{c}\text { Voltage after shunt } \\
\text { compensation } \\
\text { [p.u.] }\end{array}$ \\
\hline 1204 & 132 & 0.893 & 0.943 \\
CHANDPUR1 & 33 & 0.899 & 0.927 \\
CHANDPUR2 & 33 & 0.899 & 0.946 \\
CHNAWAB1 & 33 & 0.888 & 0.92 \\
CHNAWAB2 & 33 & 0.888 & 0.92 \\
CHNAWAB3 & 33 & 0.888 & 0.92 \\
CHNAWAB4 & 33 & 0.87 & 0.926 \\
COMILLAN1 & 33 & 0.893 & 0.915 \\
\hline
\end{tabular}




\begin{tabular}{|c|c|c|c|}
\hline COMILLAN2 & 33 & 0.875 & 0.944 \\
\hline COMILLAS1 & 33 & 0.885 & 0.91 \\
\hline COMILLAS2 & 33 & 0.885 & 0.91 \\
\hline COMILLAS3 & 33 & 0.885 & 0.91 \\
\hline COMILLAS4 & 33 & 0.885 & 0.935 \\
\hline DHANMON1 & 33 & 0.895 & 0.939 \\
\hline DHANMON2 & 33 & 0.895 & 0.939 \\
\hline DHANMON3 & 33 & 0.895 & 0.915 \\
\hline FARIDPUR1 & 33 & 0.898 & 0.923 \\
\hline FARIDPUR2 & 33 & 0.883 & 0.935 \\
\hline GOPALG1 & 33 & 0.874 & 0.926 \\
\hline GOPALG2 & 33 & 0.874 & 0.926 \\
\hline HSTEEL11_1 & 11 & 0.878 & 0.973 \\
\hline HSTEEL11_2 & 11 & 0.878 & 0.979 \\
\hline HSTEEL575_1A & 0.57 & 0.816 & 0.968 \\
\hline HSTEEL575_1B & 0.57 & 0.817 & 0.969 \\
\hline HSTEEL575_2A & 0.57 & 0.816 & 0.968 \\
\hline HSTEEL575_2B & 0.57 & 0.816 & 0.968 \\
\hline HSTEEL575_3A & 0.57 & 0.816 & 0.974 \\
\hline HSTEEL575_3B & 0.57 & 0.817 & 0.975 \\
\hline HSTEEL575_4A & 0.57 & 0.816 & 0.974 \\
\hline HSTEEL575_4B & 0.57 & 0.814 & 0.923 \\
\hline HSTEEL575_5A & 0.57 & 0.835 & 0.99 \\
\hline HSTEEL575_5B & 0.57 & 0.833 & 0.939 \\
\hline JAMALPUR1 & 33 & 0.856 & 0.908 \\
\hline JAMALPUR2 & 33 & 0.856 & 0.927 \\
\hline JAMALPUR3 & 33 & 0.856 & 0.936 \\
\hline JOYDEVP1 & 33 & 0.899 & 0.918 \\
\hline JOYDEVP2 & 33 & 0.899 & 0.918 \\
\hline JOYDEVP3 & 33 & 0.899 & 0.918 \\
\hline KABIRP1 & 33 & 0.873 & 0.946 \\
\hline KALYANP1 & 33 & 0.872 & 0.937 \\
\hline KALYANP2 & 33 & 0.872 & 0.937 \\
\hline KALYANP3 & 33 & 0.872 & 0.937 \\
\hline KAMRANG1 & 33 & 0.895 & 0.919 \\
\hline KAMRANG2 & 33 & 0.895 & 0.919 \\
\hline KISHORG1 & 33 & 0.888 & 0.912 \\
\hline KISHORG2 & 33 & 0.888 & 0.912 \\
\hline KISHORG3 & 33 & 0.888 & 0.912 \\
\hline KSTEEL33_1 & 33 & 0.867 & 0.975 \\
\hline KSTEEL33_2 & 33 & 0.888 & 1.028 \\
\hline LALMONIR1 & 33 & 0.869 & 0.944 \\
\hline LALMONIR2 & 33 & 0.869 & 0.944 \\
\hline MADARIP1 & 33 & 0.885 & 0.909 \\
\hline MADARIP2 & 33 & 0.885 & 0.909 \\
\hline MANIKG1 & 33 & 0.88 & 0.929 \\
\hline MANIKG2 & 33 & 0.88 & 0.907 \\
\hline MANIKNAG1 & 33 & 0.887 & 0.901 \\
\hline MIRPUR2 & 33 & 0.883 & 0.947 \\
\hline MIRPUR3 & 33 & 0.876 & 0.939 \\
\hline
\end{tabular}

\begin{tabular}{llll}
\hline MOGHBAZ1 & 33 & 0.885 & 0.904 \\
MOGHBAZ2 & 33 & 0.885 & 0.904 \\
MYMENS1 & 33 & 0.882 & 0.956 \\
MYMENS2 & 33 & 0.882 & 0.956 \\
MYMENS3 & 33 & 0.882 & 0.956 \\
NAOGAON1 & 33 & 0.891 & 0.98 \\
NAOGAON2 & 33 & 0.877 & 0.963 \\
NAOGAON3 & 33 & 0.824 & 0.936 \\
NARINDA1 & 33 & 0.896 & 0.911 \\
NARINDA2 & 33 & 0.896 & 0.911 \\
NETRO1 & 33 & 0.856 & 0.948 \\
NETRO2 & 33 & 0.856 & 0.948 \\
PALASHB1 & 33 & 0.868 & 0.947 \\
PALASHB2 & 33 & 0.867 & 0.947 \\
PATUAKHA3 & 33 & 0.888 & 0.932 \\
RAJSHA1 & 33 & 0.898 & 0.926 \\
TANGAIL2 & 33 & 0.864 & 0.925 \\
ULLON1 & 33 & 0.884 & 0.936 \\
UTTARA2 & 33 & 0.896 & 0.918 \\
\hline
\end{tabular}

Table 2. Added Values of Shunt Capacitor.

\begin{tabular}{|c|c|c|c|}
\hline Shunt Capacitor & $\begin{array}{c}\mathbf{Q} \\
\text { MVAR }\end{array}$ & $\begin{array}{c}\text { Rated } \\
\mathbf{k V}\end{array}$ & $\begin{array}{c}\text { Capacitance } \\
(\mu \mathrm{F})\end{array}$ \\
\hline CHANDPUR02 & 12.25 & 33 & 35.80620911 \\
\hline CHNAWAB4 & 5.4 & 33 & 15.78396157 \\
\hline COMILLAN2 & 6.8 & 33 & 19.87609975 \\
\hline COMILLAS4 & 8.25 & 33 & 24.11438573 \\
\hline DHANMON01 & 16.12 & 33 & 47.11804824 \\
\hline DHANMON02 & 16.12 & 33 & 47.11804824 \\
\hline FARIDPUR02 & 9 & 33 & 26.30660261 \\
\hline GOPALG1 & 3.3 & 33 & 9.645754291 \\
\hline GOPALG2 & 3.3 & 33 & 9.645754291 \\
\hline HSTEEL11_1 & 6 & 11 & 157.8396157 \\
\hline HSTEEL11_2 & 8 & 11 & 210.4528209 \\
\hline HSTEEL575_-0 & 3.31 & 0.57 & 32428.61623 \\
\hline HSTEEL575_-1 & 3.31 & 0.57 & 32428.61623 \\
\hline HSTEEL575_1A & 3.31 & 0.57 & 32428.61623 \\
\hline HSTEEL575_1B & 3.31 & 0.57 & 32428.61623 \\
\hline HSTEEL575_2 & 0.013 & 0.575 & 125.1577646 \\
\hline HSTEEL575_3 & 0.013 & 0.575 & 125.1577646 \\
\hline HSTEEL575_3A & 3.31 & 0.57 & 32428.61623 \\
\hline HSTEEL575_4A & 3.31 & 0.57 & 32428.61623 \\
\hline JAMALPUR2 & 6.5 & 33 & 18.999213 \\
\hline JAMALPUR3 & 9.3 & 33 & 27.18348937 \\
\hline KABIRP1 & 16.6 & 33 & 48.52106704 \\
\hline KALYANP1 & 24.7 & 33 & 72.19700939 \\
\hline KALYANP2 & 24.7 & 33 & 72.19700939 \\
\hline KALYANP3 & 24.7 & 33 & 72.19700939 \\
\hline KSTEEL33_02 & 6 & 33 & 17.53773508 \\
\hline
\end{tabular}




\begin{tabular}{lccc}
828 & & & N. SAHADAD \\
\hline KSTEEL33_1 & 12.25 & 33 & 35.80620911 \\
LALMONIR1 & 5.5 & 33 & 16.07625715 \\
LALMONIR2 & 5.5 & 33 & 16.07625715 \\
MANIKG1 & 10.4 & 33 & 30.3987408 \\
MIRPUR2 & 23.4 & 33 & 68.39716679 \\
MIRPUR3 & 23.4 & 33 & 68.39716679 \\
MYMENS1 & 11 & 33 & 32.1525143 \\
MYMENS2 & 11 & 33 & 32.1525143 \\
MYMENS3 & 11 & 33 & 32.1525143 \\
NAOGAON1 & 12 & 33 & 35.07547015 \\
NAOGAON2 & 12 & 33 & 35.07547015 \\
NAOGAON3 & 12 & 33 & 35.07547015 \\
NETRO1 & 6.5 & 33 & 18.999213 \\
NETRO2 & 6.5 & 33 & 18.999213 \\
PALASHB1 & 5.5 & 33 & 16.07625715 \\
PALASHB2 & 5.5 & 33 & 16.07625715 \\
PATUAKHA3 & 3.5 & 33 & 10.23034546 \\
TANGAIL2 & 11 & 33 & 32.1525143 \\
ULLON1 & 15.6 & 33 & 45.5981112 \\
\hline
\end{tabular}

\section{Conclusions}

The demand of power is increasing enormously day by day. So it has been difficult task to maintain the power quality with the increasing load. As system redesign is much costly so it is necessary to control the parameters of the power system to obtain maximum efficiency.

In this paper such a cost effective shunt compensation method is applied to Bangladesh power system. Here fixed capacitors are used as a shunt compensator to solve the under voltage problem of Bangladesh power system. The under voltage problem is solved successfully and power factor of the system also improved.

\section{References}

[1] B. M. Zhang and Q. F. Ding, "The Development of

FACTS and Its Control," Advances in Power System Control, Operation and Management, APSCOM-97. 4th International Conference, Vol. 1, Beijing, 11-14 November 1997, pp. 48-53.

[2] J. J. Paserba, "How FACTS Controllers Benefit AC Transmission Systems," Power Engineering Society General Meeting, IEEE, Vol. 2, Warrendale, 10 June 2004, pp. 1257-1262.

[3] A. Edris, "FACTS Technology Development: An Update," Power Engineering Review, IEEE, Vol. 20, No. 3, March 2000, pp. 599-627.

[4] L. Gyugyi, "Application Characteristics of ConverterBased FACTS Controllers," IEEE Conference on Power System Technology, Vol. 1, Perth, 4-7 December 2000, pp. 391-396.

[5] H. Dag, B. Ozturk and A.Ozyurek, "Application of Series and Shunt Compensation to Turkish National Power Transmission System to Improve System Loadability," ELECO'99 Intenational Conference on Electrical and Electronic Engineering, Bursa, 1-5 December 1999, pp. 243-247.

[6] J. R. Daconti and D. C. Lawry, "Increasing Power Transfer Capability of Existing Transmission Lines," Transmission and Distribution Conference and Exposition, IEEE PES, Vol. 3, Schenectady, 7-12 September 2003, pp. 1004-1009.

[7] R. Rajarman, F. Alvarado, A. Maniaci, R. Camfield and S. Jalali, "Determination of Location and Amount of Series Compensation to Increase Power Transfer Capability," IEEE Transactions on PowerSystems, Vol. 3, No. 2, 1998, pp. 294-300. doi:10.1109/59.667338

[8] R. S. Naik, K. Vaisakh and K. Anand., "Determination of ATC with PTDF Using Linear Methods in Presence of TCSC," The 2nd International Conference on Computer and Automation Engineering, Vol. 5, Singapore, 26-28 February 2010, pp. 146-151.

[9] N. G. Hingorani and L. Gyugyi, "Understanding FACTS, Concepts and Technology of Flexible AC Transmission systems," IEEE Press, New York, 2000.

[10] J. Grainger and W. Stevenson, "Power System Analysis," McGraw-Hill, New York, 1994. 